\title{
Understanding, Assessing and Treating Prospective Memory Dysfunctions in Traumatic Brain Injury Patients
}

\author{
Giovanna Mioni, Shawn M. McClintock and \\ Franca Stablum \\ Additional information is available at the end of the chapter \\ http://dx.doi.org/10.5772/57307
}

\section{Introduction}

Our capacity to shape and direct our future behaviour is of fundamental importance in the development, pursuit, and maintenance of independence and autonomy from early childhood to late adulthood. A cognitive ability required for those functions is prospective memory (PM), which is the ability to form and remember to prospectively perform the intended action $[1,2]$. Researchers have extensively focused on PM impairment in patients with traumatic brain injury (TBI) [3]. However, there has been limited research into the assessment and treatment of PM impairment in TBI patients. Reliable and valid tests with normative data are necessary for health professionals working with people with PM impairments. This chapter reviews the principal findings on PM impairment in TBI patients, and the main procedures used to assess and rehabilitate PM.

\section{Prospective Memory}

Prospective Memory (PM) refers to the cognitive ability to form and remember to perform an intended action at a specific moment in the future [1,2]. That cognitive ability is essential for many daily activities, such as remembering to pick up something at the market after work, send a gift for a birthday, or call a friend at a specific time. Although past researchers tended to characterize PM as a unitary process, it is very complex and comprised of various components [4]. For example, consider the situation in which a principal asks a teacher to relay a message to a student. The teacher has committed him/herself to two memory tasks: one is to remember the content of the message, and the second is to deliver it as soon as he/she sees the 
student. Remembering the content of a PM task is essential to perform the PM task, which researchers refer to as the content of a PM task (retrospective component). However, remembering only the content of the PM task will not produce successful performance. The action must also be performed at the appropriate moment in the future. This is referred to as the prospective component of PM tasks. Thus, a critical aspect to success on PM tasks is not only recalling the content of the intended action, but also performing the action at the appropriate moment in the future [4].

A four stages model has been proposed to explain the functioning of PM [1, 4-6]:

1. Intention formation - the first phase consists on the formation of the delayed intention, which often involves forming a plan. Different degrees of motivation may influence the strength of encoding the delayed intention. In fact, the strength of an intention may reflect not only the personal importance, but also the potential benefits and costs of realizing the delayed intention.

2. Intention retention - the retention intervals describe the delay between the formation of and execution of the intended action. The retention interval, most of the time, is filled with an "ongoing task" [7]. Some authors found lower performance after a long relative to a short delay [8], though others failed to find an association between delay length and decline [9, 10] or improvement in performance [11]. In addition to the length of the delay interval, the cognitive load added during the delay interval (filled or un-filled intervals) may influence performance $[7,9]$.

3. Intention initiation - the point in time at which execution of the intention is (or should be) initiated. Successful performance on PM tasks, not only required to accurately encode the intended action and maintain the intended action active during the interval delay, but also to recognize the cue, retrieve the action associated with that intention, and perform the action. People may fail on their performance not only because they fail to recall the intended action when the target occurs, but also because their cognitive resources were captured by the demands of the ongoing task.

4. Intention execution - where and when the intended action is executed. This may be considered the final stage with the execution of the delayed intention. However, successfully completing all previous phases, errors can occur and the delayed intention may not be performed. Distractions or failure to complete the task due to external circumstances may compromise performance. For example, the intention to phone a friend may fail because of interruption by the doorbell or the friend was not at home. When the delayed intention is not executed, it is necessary to re-establish the intended action and re-form the plan [1].

A fifth phase, Evaluation of outcome was proposed and is concerned with monitoring the output of the execution of the intended action. The evaluation of outcome describes the process by which a person checks if the intended action has been accurately performed [1].

According to Einstein and McDaniel's model [12], there are two types of PM targets, eventbased and time-based tasks ${ }^{1}$, that trigger the execution of our delayed intention. In conditions that require event-based PM, a person performs an action when a specific event occurs (i.e. 
passing a message when a friend calls); while in situations that require time-based PM, the action has to be performed at a specific time in the future (i.e. remembering the appointment with a friend at 4:00 p.m.) [12]. Event-based PM tasks are considered to be less cognitively demanding than time-based PM tasks because they require less self-initiated retrieval and external cue(s) are available to help recall the task [13, 14].

\subsection{Prospective memory in traumatic brain injury patients}

It has been suggested that the prefrontal cortex predominantly mediates executive control mechanisms [15], which are required to successfully initiate and execute the intended action $[5,13,14,16]$. Because of this link between executive functions and the prefrontal cortex, and because prefrontal areas are commonly damaged after a TBI, it is not surprising that individuals with TBI are often impaired on PM tasks [3]. For individuals with TBI, frequent PM failures (e.g., forgetting to repay a loan to a friend, maintain an appointment, take medication, turn off the stove) can be frustrating, embarrassing and in some cases, life threatening. These failures have the potential to limit the independence of these individuals, causing them to rely on a carer for prompting and completion of activities and instrumental activities of daily living. Moreover, these failures may affect their opportunity to return to work or start a new vocation $[3,17,18]$.

Impairment of PM in TBI patients would differ according to the complexity and requirement of the tasks [7, 19]; moreover, when tested both on event- and time-based tasks, TBI patients are particularly impaired on time-based tasks consistent with the idea that those tasks require more self-initiation. Dysfunctions on time-based tasks may also be due to less strategic monitoring behaviour engaged by TBI patients $[1,4,16]$.

The earliest studies that examined the effect of TBI on PM performance used self-rating scales [20] or few PM items [21, 22]. In those studies, the Prospective Memory Questionnaire (PMQ) was tested along with attentional and memory tasks [20]. Adults with TBI and older adults performed more poorly than younger adults on short-term PM tasks, and TBI patients rated themselves more poorly than younger adults. Two PM tasks were used to assess PM performance [22]: the first task involved telling the participants about a selfreport memory questionnaire at the beginning of an assessment session and instructing them to ask for the questionnaire at the end of the session (even-based task). The second task involved asking the participants to return (by mail) an evaluation form with the date written in the top corner (time-based task). Because of the small number of items used and the correct/incorrect nature of these items, the PM scores obtained with these tasks were limited in range and thus were unreliable [23].

To assess PM more reliably and accurately, it is necessary to increase either the number of items used or the number of responses required for each item. Recent studies considered these limitations and developed more appropriated tasks to investigate the effects of TBI on eventand time-based PM performance (Table 1). 


\begin{tabular}{|c|c|c|c|c|c|c|c|}
\hline & \multicolumn{5}{|c|}{ TBI characteristics } & \multicolumn{2}{|c|}{ Type of prospective memory tasks } \\
\hline Study ${ }^{1}$ & Year & Sample & GCS & $\begin{array}{l}\text { Time since } \\
\text { injury } \\
\text { (months) }\end{array}$ & NPS assessment ${ }^{2,3}$ & Event-based & Time-based \\
\hline [25] & 1999 & $\begin{array}{l}12 \mathrm{TBI} \text { and } 12 \\
\text { controls }\end{array}$ & 8 or less & $24.58(15.58)$ & - & $\begin{array}{l}\text { Response to } \\
\text { questions and the } \\
\text { target word }\end{array}$ & $\begin{array}{l}\text { Press a key every } 5 \\
\text { min and monitor the } \\
\text { time }\end{array}$ \\
\hline [26] & 2001 & $\begin{array}{l}13 \mathrm{TBI} \text { and } 13 \\
\text { controls }\end{array}$ & $6.6(3.3)$ & $1.8(0.7)$ & $\begin{array}{c}\text { WCST, COWAT and } \\
\text { DASS }\end{array}$ & $\begin{array}{c}\text { Deliver a message } \\
\text { (unfilled and filled } \\
\text { conditions) }\end{array}$ & $\begin{array}{l}\text { Stop the timer after } 5 \\
\text { min (unfilled and } \\
\text { filled conditions) }\end{array}$ \\
\hline [28] & 2003 & $\begin{array}{l}14 \mathrm{TBI} \text { and } 14 \\
\text { controls }\end{array}$ & 3 to 15 & $9.71(7.5)$ & $\begin{array}{l}\text { TOL, COWAT and } \\
\text { LNST }\end{array}$ & $\begin{array}{l}\text { Response to a cue } \\
\text { (low and high } \\
\text { cognitive demand) }\end{array}$ & - \\
\hline [11] & 2004 & $\begin{array}{c}16 \mathrm{TBI} \text { and } 16 \\
\text { controls }\end{array}$ & 8 or less & 108 & - & $\begin{array}{c}\text { Perform actions } \\
\text { when the target } \\
\text { appeared (related- } \\
\text { unrelated cues) } \\
\text { (10 vs. } 45 \text { min } \\
\text { delay) }\end{array}$ & $\begin{array}{l}\text { Perform actions after } \\
\text { the interval (related- } \\
\text { unrelated cues) } \\
\text { (10 vs. } 45 \text { min delay) }\end{array}$ \\
\hline [19] & 2004 & $\begin{array}{l}7 \mathrm{TBI}, 21 \text { older } \\
\text { and } 19 \\
\text { younger } \\
\text { controls }\end{array}$ & severe & $41.71(11.79)$ & $\begin{array}{l}\text { Verbal intelligence } \\
\text { and WCST }\end{array}$ & $\begin{array}{l}\text { Complex tasks } \\
\text { following the } \\
\text { multiprocess } \\
\text { model }\end{array}$ & - \\
\hline [29] & 2004 & $\begin{array}{c}24 \mathrm{TBI} \text { and } 24 \\
\text { controls }\end{array}$ & 8 or less & $25.75(21.63)$ & $\begin{array}{l}\text { Digit span forward } \\
\text { and backward, TMT, } \\
\text { LM Visual } \\
\text { recognition, COWAT, } \\
\text { Stroop, WCST }\end{array}$ & $\begin{array}{l}\text { Press a designed } \\
\text { key on focal cue or } \\
\text { peripheral cue }\end{array}$ & - \\
\hline [27] & 2005 & $\begin{array}{c}25 \text { TBI and } 25 \\
\text { controls }\end{array}$ & 8 or less & 7 & $\begin{array}{l}\text { Visual (Story sub-test, } \\
\text { RAVLT) and verbal } \\
\text { (Pictures, Faces and } \\
\text { Routes sub-tests of } \\
\text { RBMT) declarative } \\
\text { memory, digit span, } \\
\text { TMT, COWAT and } \\
\text { WCST }\end{array}$ & RBMT & $\begin{array}{l}\text { Stop a timer and } \\
\text { send the envelop }\end{array}$ \\
\hline [7] & 2007 & $\begin{array}{l}17 \mathrm{TBI} \text { and } 16 \\
\text { controls }\end{array}$ & $11.67(3.50)$ & $41.28(32.52)$ & - & $\begin{array}{l}\text { Response to a cue } \\
\text { (one or four cue } \\
\text { targets) }\end{array}$ & - \\
\hline [18] & 2008 & $\begin{array}{l}44 \text { TBI but no } \\
\text { controls }\end{array}$ & $7.08(3.89)$ & - & $\begin{array}{l}\text { TMT, COWAT and } \\
\text { metacognitive } \\
\text { variables }\end{array}$ & CAMPROMPT & CAMPROMPT \\
\hline
\end{tabular}




\begin{tabular}{|c|c|c|c|c|c|c|c|}
\hline & \multicolumn{5}{|c|}{ TBI characteristics } & \multicolumn{2}{|c|}{ Type of prospective memory tasks } \\
\hline Study ${ }^{1}$ & Year & Sample & GCS & $\begin{array}{l}\text { Time since } \\
\text { injury } \\
\text { (months) }\end{array}$ & NPS assessment ${ }^{2,3}$ & Event-based & Time-based \\
\hline [24] & 2010 & $\begin{array}{c}31 \mathrm{TBI} \text { and } 31 \\
\text { controls }\end{array}$ & $13-15$ & $0.89(0.22)$ & - & MIST & MIST \\
\hline [16] & 2012 & $\begin{array}{c}18 \mathrm{TBI} \text { and } 18 \\
\text { controls }\end{array}$ & $6.77(2.13)$ & $24.50(19.67)$ & Stroop and N-Back & - & $\begin{array}{c}\text { Press a key every } 5 \\
\text { min and monitor the } \\
\text { time }\end{array}$ \\
\hline
\end{tabular}

${ }_{1}$ Studies included here have been conducted with behavioral measures.

${ }_{2}$ References of neuropsychological tests are not reported because the authors referred to different versions. Please refer to the specific articles for the appropriate references.

${ }_{3}$ Appendix A reports the full name of neuropsychological tasks employed in the studies with a brief description.

Table 1. Studies that used behavioural tasks to investigate PM performance on TBI patients. GCS = Glasgow Coma Scale (Scores < 8 = severe; scores 9-12 = moderate; scores 13-15= mild); Time refers to the time post injury (months); NPS assessment refers to the neuropsychological tasks included in the studies; WCST = Wisconsin Card Sorting Test; COWAT = Controlled Oral Word Association Test; DASS = Depression, Anxiety, Stress Scale; TOL = Tower of London; LNST = Letter-Number Sequencing Test; TMT = Trial Making Test; RBMT = Rivermead Behavioural Memory Test; CAMPROMPT = Cambridge Behavioural Prospective Memory Test; MIST = Memory for Intention Screening Test.

Among the studies identified ${ }^{2}$, only one included patients with mild TBI [24]. Most studies included have evaluated event-based PM performance, 6 examined both event- and timebased performance, and one only analyzed time-based PM performance. When both event- and time-based tasks were included in the studies, TBI patients obtained lower performance on time-based PM tasks [11, 25-27], which substantiated that time-based tasks are more difficult to execute probably due to more self-initiated retrieval impairment [12]. Generally, TBI patients showed PM dysfunctions compared to healthy controls, but the degree of impairment varied according to the characteristics of the employed tasks. By varying the cognitive demand on the ongoing task TBI patients performed more poorly than controls on the high, but not low demand condition [28]. Some authors also manipulated the salience of the event cue in PM performance [29]. The cue was either integrated (focal cue) or peripheral (no-focal cue) to the ongoing working memory task. TBI patients and controls showed no differences on the ongoing task, but PM performance was poorer in TBI patients in both focal and peripheral cue conditions. That finding suggested that even with highly salient cues, TBI patients exhibit PM failures. Moreover, both TBI and controls self-reported that greater monitoring effort was required for the peripheral, rather than for the focal-cue condition. Instead, when the cue is maintained in a focal condition, but is varied the number of distractions during the ongoing task, TBI patients performed more poorly both on one and four target conditions [7]. Finally, some authors have varied the delay between encoding and task performance (10 vs $45 \mathrm{~min}$ ) expecting lower performance in the longer delay condition. Researchers have also manipulated the functional link (semantic inter-item associative link) between intended actions with the expectation that 
performance would improve. Patients with TBI performed significantly lower than controls; however, there were no significant effects of delay interval or functional link of the intended actions [11].

A subset of studies included executive functions tasks to determine whether impairment on PM was associated with executive dysfunctions. The available evidences were mixed regarding the relationship between PM and executive functions, as some studies found significant [16, 22,28] and others no [27] association between those two constructs. For example, we found [16] that working memory significantly correlated with PM accuracy only in TBI patients, while inhibition was involved in controls. Also, working memory significantly correlated with PM performance in the low cognitive demand condition in both TBI and controls [28]. These results suggested that for the employed dual-task event-based paradigm, participants had to actively maintain in memory the requirement while undertaking the ongoing task [16, 28]. Spontaneous flexibility assessed through the Controlled Oral Word Association Test (COWAT) [30] significantly correlated with event-based PM performance in the high-demand condition in TBI patients. TBI event-based PM performance significantly correlated with attention/speed processing tasks, which added further support to the notion of a strong relationship between attention and PM performance [29, 31]. In particular, the authors pointed out that those PM dysfunctions may be due to momentary lapses of attention to task details rather than to complete forgetting of the task instructions. Retrospective memory also accounted for a significant amount of variance in PM tasks of TBI patients independent of executive functions [25]. In particular, it was found that executive functions were involved both on time- and event-based PM performance, but it particularly influenced time-based PM performance, whereas retrospective memory contributed most to event-based performance. Finally, a complex PM paradigm was adopted $[19,32]$ to investigate which of the four phases of PM were affected in TBI patients. Impairment of PM was found on intention formation, intention re-instantiation, and intention execution. That finding confirmed that executive functions are involved on these three phases rather than only on intention retention. Only one study investigated theinvolvement of temporal abilities in time-based PM performance and found that adequate temporal abilities were involved in monitoring behavior rather than PM [16].

In addition, two studies have investigated PM performance according to demographic, clinical and metacognitive variables $[18,25]$. Depressive symptoms were found to adversely affect successful performance on the timing component of the time-based task [20], while anxiety symptoms adversely affected performance on event-based tasks [25]. In a more recent study, the localization of the damage (mainly frontal) significantly correlated with event-based Cambridge Test of Prospective Memory (CAMPROMPT) scores, whereas duration of posttraumatic amnesia (PTA) and metacognitive variables significantly correlated with both timeand event-based scores [18].

\subsection{Virtual tasks to investigate prospective memory in TBI patients}

For adequate clinical assessment and rehabilitation programs, neuropsychologists need information about how a patient functions in routine daily activities, and laboratory-based tasks may be unable to always provide such information [33]. Chaytor and SchmitterEdgecombe (2003) found that the relationship between neuropsychological tests and measures 
of outcome is often limited. Recently, it was concluded that most PM tasks lack adequate reliability [23]. As a consequence, it is often impossible to translate test scores into either goals for rehabilitation or conclusions about the level of impairment; that is, many conventional tests of memory-related abilities lack ecological validity [23, 33, 34]. To solve this important discrepancy between performance on neuropsychological tests and performance in everyday life, researchers, following the evolution of computer programs, have developed tasks that can bridge conventional neuropsychological tests with behavioral observations. Virtual tasks, in fact, can simulate the activity of everyday life in a controlled setting [33].

\begin{tabular}{|c|c|c|c|c|c|c|}
\hline Study & Year & Sample & GCS & $\begin{array}{l}\text { Time since } \\
\text { injury } \\
\text { (months) }\end{array}$ & NPS assessment ${ }^{1}$ & PM Tasks \\
\hline [38] & 2005 & $\begin{array}{c}25 \mathrm{TBI} \text { and } 20 \\
\text { controls }\end{array}$ & - & $\begin{array}{l}113.76 \\
(75.13)\end{array}$ & $\begin{array}{l}\text { NART, WCST, LM, } \\
\text { COWAT and TMT }\end{array}$ & $\begin{array}{l}\text { Videotape: Performing activities } \\
\text { when the cue appeared on the } \\
\text { screen by saying to the experimenter } \\
\text { the activities required }\end{array}$ \\
\hline [37] & 2005 & $\begin{array}{l}2 \text { brain injury } \\
\text { patients }{ }^{2} \text { and } 3 \\
\text { controls }\end{array}$ & $\begin{array}{l}\text { Patients SR } \\
\text { GCS }=3 \text { and } \\
\text { Patients TJ } \\
\text { GCS }=4\end{array}$ & $\begin{array}{l}\text { Patients SR } 6 \\
\text { months; } \\
\text { Patients TJ } \\
3.5 \text { months }\end{array}$ & $\begin{array}{l}\text { Word list from } \\
\text { WMS, Digit span, } \\
\text { Stroop, WCST and } \\
\text { NART }\end{array}$ & $\begin{array}{l}\text { Virtual Street: Imagine walking on a } \\
\text { street and performing } 3 \text { activities. } \\
\text { The list of activities was either visible } \\
\text { or hidden after instruction }\end{array}$ \\
\hline [39] & 2006 & $\begin{array}{c}20 \mathrm{TBI} \text { and } 20 \\
\text { controls }\end{array}$ & - & $\begin{array}{c}160.2 \\
(91.66)\end{array}$ & $\begin{array}{l}\text { DEX, Logical } \\
\text { memory from WMS } \\
\text { and Ruff } 2 \& 7 \\
\text { selective attention } \\
\text { test }\end{array}$ & $\begin{array}{l}\text { Virtual Street: Imagine being a street } \\
\text { inspector and performing } 3 \text { activities } \\
\text { under low and high distraction. } \\
\text { Moreover performing } 10 \text { errands }\end{array}$ \\
\hline [40] & 2009 & $\begin{array}{c}16 \mathrm{TBI} \text { and } 16 \\
\text { controls }\end{array}$ & 8 or less & $\begin{array}{l}\text { at least } 3 \\
\text { month }\end{array}$ & $\begin{array}{l}\text { HVLT, TMT and } \\
\text { Digit span }\end{array}$ & $\begin{array}{l}\text { The supermarket shopping trip: } \\
\text { "buy" } 8 \text { items while watching a 8- } \\
\text { min DVD of a supermarket trip }\end{array}$ \\
\hline [44] & 2013 & $\begin{array}{c}18 \mathrm{TBI} \text { and } 18 \\
\text { controls }\end{array}$ & $4.54(1.37)$ & $\begin{array}{c}66.94 \\
(95.22)\end{array}$ & $\begin{array}{l}\text { Phonemic and } \\
\text { Semantic fluency; } \\
\text { TMT; WCST }\end{array}$ & Virtual Week \\
\hline
\end{tabular}

${ }_{1}$ References of neuropsychological tasks are not reported because the authors referred to different version of the tasks. Please refer to the specific articles for the appropriate references.

${ }_{2}$ The study includes 3 patients with brain injury: SR suffered a severe TBI as a result of assault, TJ suffered a TBI as a result of motor vehicle accident and RW suffered cerebellar and sub-arachnoid haemorrhages. Only information on patients SR and TJ were included because TBI patients.

Table 2. Studies that used ecological tasks to investigate PM performance on TBI patients. GCS = Glasgow Coma Scale; NPS assessment refers to the neuropsychological tasks included in the studies; NART = National Adults Reading Test; WCST = Wisconsin Card Sorting Test; LM = Logic Memory; COWAT = Controlled Oral Word Association Test; TMT = Trial Making Test; WMS = Wechsler Memory Scale; DEX = questionnaire from the Behavioural Assessment of Dyexecutive Syndrome; HVLT = Hopkins Verbal Learning Test. 
In Table 2 are revised studies that were conducted with virtual tasks. This literature is presented separately from other studies on PM because it is more representative of everyday PM performance, and focused on filling the gap between performance on laboratory tasks and PM performance in real life.

The Prospective Remembering Video Procedure (PRVP) was designed to test PM abilities in virtual street simulation [35]. The task involves remembering to carry out a set of activities while watching a videotape filmed by a person walking slowly through a shopping complex. Participants virtually visited a shopping centre, with a set of event-based activities, each of which involved an action ('buy a record') and a cue ('from the record stand'). As each cue comes into view, the associated action must be recalled. The view that was presented focused mostly on the shop-front, although the footage also included views of passengers crossing the street. Studies conducted with health students and mix-brain injury patients demonstrated that the PRVP procedure was reliable and easier to complete when the video was set in a familiar location. Moreover, it was found that the video-based task was correlated with performance on an equivalent real life memory task, and provided evidence for criterion validity $[35,36,37]$. Twenty severe TBI patients and 20 matched controls were also tested with PRVP and completed the ongoing and PM tasks while "walking" along the street. Severe TBI patients showed poorer performance and were more affected by distractions on the PM tasks compared to controls [38]. Previous findings were confirmed and extended with a Virtual Street task [37, 38, 39]. Results showed that TBI patients performed more poorly than the control group on the PM tasks, but had similar performance on the Wechsler Memory Scale ( $3^{\text {rd }}$ Edition) Logical Memory subtest. The authors discussed this result in favor of sensitivity of the Virtual Street task to measure PM performance. These results also suggested that TBI patients may show normal performance on memory tests, particularly in a controlled and quiet setting, but when memory performance is tested in a less controlled setting with distractors and tasks that require more strategic processes (like in real life conditions), real TBI dysfunctions may emerge [39].

Interesting, following the idea to create tasks more representative to real life situations, other authors have investigated the "generation effect", which refers to the effect of people demonstrating better memory for self-generated material than for experimenter-generated materials [40, 41, 42]. Considering the instructions often presented in PM setting to perform the action at a specific time or when a specific cue occurs, these instructions may allow control over the tasks, but they are unable to produce the same level of motivation in participants compared to self-generated activities [42]. Some authors reasoned whether people with TBI were more likely to remember a PM task if it is self-generated as opposed to experimenter-generated [40]. TBI patients were less accurate than controls, but the source of the to-be-remembered item exerted minimal influence on PM performance in both TBI patients and controls. Additional analyses were conducted to further investigate the source of errors, and it was found that both groups were able to recognize at post-test the shopping item they had intended to buy, but TBI patients failed to activate their intention to buy the intended item at the appropriate time. Moreover, significant correlations were found between working memory, attention-set 
shifting and PM performance, which provided further support to the notion that higher order cognitive functions are necessary in PM [19, 40, 42].

Although they showed a high level of correspondence with real-life situations, the PRVP and the Virtual Street required participants to perform only event-based tasks. This was a limitation as PM performance should be investigated both with event- and time-based tasks. To resolve these limitations, the Virtual Week task was developed [42]. This task simulates daily life activities in a board game, where participants move around the board with the roll of a dice. Each circuit around the board represents one virtual day. Participants are required to perform 10 PM activities each virtual day (5 virtual days from Monday to Friday; additional information about the task procedures are presented in the section "Behavioral measures"). We found that people with TBI had significant difficulties executing PM tasks, which were more pronounced for time-based than event-based tasks [44]. These data suggested a relatively global PM deficit in people with TBI. Of particular interest was the finding that the magnitude of TBI impairment was consistent across regular and irregular tasks. Because the key distinction between regular and irregular tasks was that they place low and high demands on retrospective memory, respectively, these data suggested that failures of retrospective memory were not the major cause of TBI-related impairment in PM [44].

Taken together, TBI patients showed PM impairment when measured with laboratory based PM tasks. Some studies have reported that TBI patients were particularly impaired when they performed time-based tasks [11, 25-27] consistent with the view that time-based tasks are demanding and require more self-initiated processes [12]. However, other studies found a more generalized PM impairment in TBI patients [3, 44]. General agreement was observed between authors concerning the involvement of executive functions in PM performance; participants with lower executive functions would also present lower PM performance [16, 22, $25,26,28,29,31,44]$. The degree of the involvement of executive functions in PM performance varies according to the task employed and cognitive load. It is important to note that some authors have observed lower correspondence between PM performance obtained with laboratory-based tasks and real life situations [23, 33, 34, 45, 46]. Studies conducted with virtual reality tasks are trying to fill this gap, but further research is required to provide reliable and valid scores, and to develop tasks that can be used in clinical settings to screen for PM performance.

\section{Assessment of prospective memory dysfunctions in clinical settings}

Reliable and valid PM tools with normative data are necessary for health professionals working with people with any type of neurological disorder to acquire reliable information regarding PM performance. Such psychometrically sound tools are important not only to evaluate the degree of PM impairment, but also to provide useful information to inform the appropriate rehabilitation program. This section provides the most commonly used tools to investigate PM in clinical settings. 


\subsection{Self-report questionnaires}

Self-report questionnaires are the most commonly employed tools to assess PM in real life situations. They assess PM dysfunctions by asking participants to rate their memory abilities by answering questions regarding their frequency of forgetting or remembering. They are particularly useful in clinical settings and in the rehabilitation process, because they can provide information about the patients' PM dysfunctions. However, it is very important to consider that a common problem after TBI is an inability to recognize impairments or disabilities that resulted from injury. This phenomenon has been termed "lack of insight" [22] or impaired "self-awareness" [47]. Self-report questionnaires have been recognized for their value in contributing to the understanding of patients' everyday PM dysfunctions; however, when used with TBI patients, impaired self-awareness may compromise the validity of selfreport measures. Useful information can be acquired from relatives or caregivers. Questionnaires completed by significant others of the patients' general PM function have been found to correlate with objective PM test scores, and reliably address the patients' PM dysfunction in daily life [17, 18, 45].

The first developed questionnaires investigated general memory dysfunction in daily life with no specific distinction between retrospective or PM dysfunctions. These questionnaires included the Memory Functioning Questionnaire [48], Inventory of Everyday Memory Functioning [49], Cognitive Failure Questionnaire [50], Everyday Memory Questionnaire [51] and the Subjective Memory Questionnaire [52].

The Prospective Memory Questionnaire (PMQ) is a 52-item questionnaire that includes four PM subscales: 1) the long-term episodic subscale is related to memory for irregularly scheduled tasks, which require completion some hours or days after a cue to perform it (i.e. "I forgot to return books to the library by the due date"), 2) the short-term habitual subscale addresses memory for tasks to be completed shortly after the relevant cue that occur on regular basis (i.e. "I forgot to put a stamp on a letter before mailing it"), 3) the internally cued subscale addresses memory for tasks that do not have a clear external cue (i.e. "I was driving and temporarily forgot where I was going"), and 4) the techniques to remember subscale measures the use of strategies to aid prospective memory (i.e. "I rehearse things in my mind so I will not forget to do them") [20]. The PMQ questionnaire was administrated to 114 younger adults, 27 older adults and 15 patients with TBI [20]. Coefficient alpha was.92 for the PMQ total score, and ranged from. 78 to. 90 for the subscales. Factor analysis confirmed the 4 -subscale structure. Testretest reliability was found to be high, $r=.88$ for the PMQ total and ranged from. 64 to. 88 for the subscales. Overall, the results found that the ratings of TBI patients were significantly different from those of controls on one of the short-term habitual subscales of the PMQ, however, very few studies have used the PMQ with TBI patients [53].

The Comprehensive Assessment of Prospective Memory (CAPM) measure was developed to evaluate the frequency of PM failure, and to evaluate the perceived amount of concern about these memory lapses and the reasons why people are successful or unsuccessful in performing PM tasks [54]. The items include both basic and instrumental activities of everyday life and are divided into three sections. Section A analyses frequency of failure (39 items; i.e. "Forgetting an appointment with your doctor or therapist", "not locking the door when leaving 
home"), and is considered to be the best section to evaluate PM dysfunction and outcome after rehabilitation [55]. Section B analyses the amount of concern about these failures (39 items; the same items used in the first session), and Section $C$ analyses the reasons associated with the success or failures of PM tasks (15 items; "I rely to other people to remind me when I have to remember to do things"). Section A was used with 33 severe TBI patients (GCS $=5.1$; PTA = 6.66 days), 33 relatives and 29 healthy controls to investigate frequency of PM failure [54]. Analyses were conducted on self-rating and informant-rating, and the difference between these two indices provided a measure of self-awareness on PM dysfunction. The results showed no significant differences between the TBI and controls' self-ratings of the frequency of PM failure. However, a significant difference was found between the informant-ratings, which suggested that relatives and/or caregivers reported higher levels of PM failure. These findings are likely to be due to the commonly found self-awareness difficulties in patients with TBI $[47,54]$. The section C was used to investigate how TBI patients perceived and self-rated the reasons for PM failure [56]. Relatives and caregivers were also asked to rate TBI patients' PM failures. One-hundred thirty-six participants were included in the study and divided into four groups: 38 severe TBI (GCS $=5.1$, PTA $=62.6$ days), 34 significant others of TBI patients, 34 controls, and 30 significant others of controls. Results showed that patients with TBI were more likely to forget planned activities; moreover, TBI patients forgot to do things when they focused on other tasks or if they considered other activities unimportant. Patients with TBI seemed also to rely more on relatives to remind them to do things. However, no significant differences were found between TBI patients and controls on reporting reason of remembering or forgetting, and indicated that TBI patients tended to overestimate their PM abilities [54, 56]. It is important to note that authors reported that some TBI patients included in the study indicated that they have difficulty understanding some questions included in section $\mathrm{C}$ and suggested to further investigate the internal consistency of the section $C$ [56]. The validity of CAMP (section A) was investigated in a study conducted with 45 patients with moderate and severe TBI (age M=30.02 years; GCS = 7.08; PTA = 47.89) and their relatives [45]. Participants also performed two tests of PM, the CAMPROMPT [57] and the Memory Intentions Screening Test (MIST) [58]. Concurrent validity was investigated by the comparison of scores on the CAPM with scores on the CAMPROMPT and MIST. Results showed that self-report CAPM scores did not significantly correlate with scores on the CAMPROMPT or MIST. TBI patients reported very few PM failures on the CAPM, but demonstrated impairments on neuropsychological testing. Interestingly, results showed that the responses provided by the relatives on CAPM correlated with CAMPROMPT and MIST performance. These findings suggested that the relative version of the CAPM has some concurrent validity when compared with performance on neuropsychological assessments, and that the relative version of the CAPM is an objective and valid measure of PM failure in TBI patients [17, 45]. To our knowledge, no studies have been conducted with TBI on section B of CAMP.

Finally, the Prospective and Retrospective Memory Questionnaire (PRMQ) was developed to investigate the rate of frequency with which patients make particular types of memory errors [59]. The PRMQ consists of 16 items that are divided into 8 categories (two items in each category) that tap different aspects of memory failure: prospective short-term self-cued, prospective short-term environmentally-cued, prospective long-term self-cued, prospective 
long-term environmentally cued, retrospective short-term self-cued, retrospective short-term environmentally-cued, retrospective long-term self-cued, and retrospective long-term environmentally-cued [59]. Different forms of the PRMQ are available for patients and caregivers. In addition to the 16 items included in the patient form, caregivers are asked to respond to four additional questions. Two of the questions concern the caregivers' frustration and two ask the caregivers to rate the patients' frustration. The PRMQ has never been used with TBI patients, but was tested with 242 healthy older adults (age $M=72.74$ years) and 155 patients with Alzheimer disease (AD; age $M=73.95$ years). One-hundred fifty-five caregivers of AD patients (age $M=56.85$ ) and younger participants (age $M=44.19$ ) were also included in the study. The split half reliability of the PRMQ conducted in younger and older adults $(n=406)$ compared the two items within each category was found to be.84. Results showed that memory dysfunction was highest for AD patients and lowest for caregivers, with younger and older adults in between. Moreover, caregivers rated PM dysfunctions of AD patients more frustrating than patients did, and PM errors were rated as significantly more frustrating than retrospective memory errors. The authors concluded that the PRMQ might be a potentially useful tool for investigating differences in frequency of prospective and retrospective memory failure in nonpatient samples, but that the questionnaire needed to be adapted to increase its sensitivity to allow for more extensive clinical use [59]. These results were extended through the testing of 87 younger adults (age $\mathrm{M}=44.11$ years) with PRMQ and with a standard laboratory procedure of PM [60]. The reliability of PRMQ was.86 (Cronbach's alpha) for the total scale,.72 for the PM scale, and.72 for the retrospective memory scale. Participants reported higher scores (higher memory failure) for the PM than retrospective memory scale. To examine whether the PRMQ scores may predict actual performance in the laboratory PM tasks, correlation analyses were conducted and showed that only the PM scale was a significant predictor for the standard laboratory PM performance. In sum, the study extended initial findings and added additional support for the validity of the PRMQ. In addition, it provided the first evidence for the utility of the PRMQ subscales in differentiating between prospective and retrospective memory task performance $[59,60]$.

To our knowledge, no other studies appear to have examined the relationships between PM performance and measures of self-awareness in TBI patients. This may reflect the unreliability of self-rated PM measures [47]. Despite previous studies that have provided good validity and reliability of questionnaires, the results are mixed when self-rated scores were compared with laboratory-based measures of PM performance [3, 56, 60, 61]. There are two important caveats to the questionnaires. First, it is important to consider that some authors have reported lower correspondence between the PM tasks used in the examination condition, and PM activities in the everyday situation. Indeed, in real word situations, people required higher levels of executive functioning to perform multiple tasks than in a controlled experimental standardized setting. Therefore, some authors have found that TBI patients showed unimpaired performance on neuropsychological PM tests, but reported impaired PM performance in real life $[45,46]$. Second, it is important to consider the selfawareness dysfunction often observed in TBI patients that might compromise the validity of TBI participants' self-report measures [22, 47]. 


\subsection{Behavioral measures}

In 2002, Shum et al. [61] published the first review about PM dysfunctions in TBI patients. The authors identified three neuropsychological tests that provided objective scores of PM, and that were used in clinical settings. These tests included the Rivermead Behavioural Memory Test (RBMT) [62], Cambridge Behavioural Prospective Memory Test (CBPMT) [63], and Memory Intentions Screening Test (MIST) [58]. More recently, a second review about PM dysfunctions in TBI patients was published [3]; despite the increasing number of studies conducted, very few studies were dedicated to the development of valid and reliable measures to investigate PM failure in clinical settings. We briefly present the main tools that were highlighted in the prior reviews $[3,61]$ and a newly developed task.

The RBMT was the first widely used task in clinical practice that explicitly tests PM performance. It includes three PM tasks: (1) remembering where a belonging is hidden and asking for it to be returned, (2) asking for the next appointment time when an alarm sounds, and (3) delivering a message. Six neurologically impaired adults (age $M=42$ years) with a length of stay in the post acute rehabilitation program that ranged from 22 to 101 days ( $M=66.2$ days) were tested with the RBMT [64]. Participants were required to perform RBMT and some reallife activities every morning with or without verbal or visual cues. Low or no significant correlations were found between the number of activities correctly performed and RBMT score, which indicated that the RBMT was an invalid predictor of PM performance. Different results were obtained in a study with a larger sample size [65]. One-hundred-nineteen participants were divided into four groups: 20 severe TBI, 29 moderate TBI, 39 mild TBI, and 31 controls. Participants performed the RBMT together with other clinical memory measures (Wechsler Memory Scale-Revised and Luria Nebraska Neuropsychological Battery). The authors found the RBMT to be an accurate and valid measure to test PM memory failure in everyday life. However, RMBT had ceiling effects when used with 25 TBI patients (10 moderate and 15 severe; age $=28.6$ years) and 25 controls [27]. In addition, the authors found that only one of the three RBMT PM items (RBMT delayed message) successfully differentiated between TBI patients and controls. Although the RBMT was widely used in clinical settings and in several neuropsychological studies, it provided only a limited range of scores and is unlikely to be sensitive to deficits in non-severe patients [27, 61, 64]. Importantly, the test does not assess time-based PM performance [62]. A new version of the RBMT, The Rivermead Behavioural Memory Test Extended Version (RBMT-E) was created by combining two parallel forms of the RBMT [66]. The idea was to develop a more demanding test that eliminated the ceiling effects and thus would be more sensitive to minor PM impairments. The RBMT-E includes 8 subtests: (1) First and second names: remembering the names of three people; (2) Appointment and belongings: retrieving to ask for two belongings previously hidden; (3) Picture recognition: recognizing 20 previously-seen pictures and distinguishing them from distractors; (4) Face recognition: recognizing 15 previously-seen faces and distinguishing them from distractors; (5) Story: recalling a story immediately and after a delay; (6) Route: remembering 7 routes immediately and after a delay; (7) Message: remembering to pick up and deliver to the correct location a message immediately and after a delay and (8) Orientation and date: answering 12 orientation questions and giving the correct date. The RBMT-E was tested with 16 TBI patients 
(age $\mathrm{M}=40.5$ years; time since injury $\mathrm{M}=47.5$ months, range 8-92 months) and 16 controls [67]. Patients included in the study were all previously evaluated with RBMT and all scored in the normal range (screening score between 9-12), but all lamented PM dysfunctions in daily life. The authors intended to compare the performances obtained with RBMT and the RBMT-E. The results, however, were mixed and inconclusive. In fact, when patients were retested with the RBMT, some participants scored outside the normal range, which indicated poor test-retest reliability. Moreover, when the analyses of RBMT-E performance were conducted on those patients who scored in the normal range at test and retest (data collected with RBMT) and compared with controls, no differences were found between groups [16].

The CBPMT includes four time-based and four event-based tasks and requires approximately 40 minutes to be completed [63]. Participants were allowed to use any strategy to remember the tasks. The time-based tasks included (1) remembering the experimenter to not forget the keys after 15 minutes; (2) requesting the tester for a newspaper after 20 minutes; (3) switching task after working for 20 minute and (4) stop working on the booklet after 3 minutes. The event-based tasks included (1) reminding the tester about five hidden objects; (2) when the alarm rings, putting a briefcase under the desk; (3) Changing pens after having completed seven filler assignments and (4) give the envelope with the message. The CBPMT was used with 36 people with mixed brain injury (age $M=35.61$ years; time since injury 75.56 months) and 28 control participants [63]. Participants also performed the EMQ along with general intelligence, attention, working memory, executive functions and retrospective memory tasks. Results showed good correlation between the CBPMT and measures of working memory and executive functions. No correlations were found between the CBPMT and EMQ in brain injury patients, but significant correlations were found with controls. Subsequently, the CBPMT was used to create the CAMPROMPT [47], which included three time-based and three-event based tasks to be completed in 25 minutes. PM tasks are executed while performing a filler activity, and participants are allowed to spontaneously use strategies (i.e. take notes). The time-based tasks included: (1) remembering his/her belongings when there were 7 minutes left to the end of the session; (2) when the timer shows 16 minutes, the participants had to remember to stop the task in 7 minutes time and (3) at 10:11 and 5 minute after the end of the session, remembering to call the reception. For the event-based tasks participants were asked (1) to return a book to the examiner when he/she came to a question about the television program 'EastEnders'; (2) to return an envelope with "MESSAGE" written on it and (3) to remind the examiner to pick up five objects that had been hidden when the session is over. The CAMPROMPT was used with 44 moderate and severe TBI patients (age $\mathrm{M}=29.64$; GCS $=7.08$ ) [18]. Participants also completed executive functions tasks and the CAMP section A. Results showed that PTA was a good predictor of PM performance, and patients with lower executive functioning showed lower PM performance with a higher degree of impairment on the time-based tasks. Overall, the CAMPROMPT showed very high reliability (Pearson $r=.99$ ) and high internal consistency (Cronbach's alpha $=.75$ ), but moderate testretest reliability (Kendall's Tau-b $=$ of .64) $[57,68]$. 
The MIST includes four event-based and four time-based tasks to be performed in 30 minute sessions while playing a word-search puzzle that serves as a distractor [58]. The 8 PM activities are balanced in terms of delay interval ( 2 or 5 minutes delay), cue (time-based or event-based), and response modality (verbal or a physical response). The MIST also includes an 8-item multiple-choice recognition test and a more naturalistic task that has to be performed in a 24hour delay (calling the examiner the next day and report how many hours of sleep the night before). The MIST test has been widely used with healthy older adults and various clinical populations [58]. No significant correlation was found between the MIST score and CAMP in 45 moderate and severe TBI patients (age $\mathrm{M}=30.02$ years; $\mathrm{GCS}=7.08$; PTA $=47.89$ ) and their relatives, but TBI patients showed lower performance on the time-based tasks [45]. The MIST task was used with 38 mild TBI (mTBI) patients (age M= 40.6 years, GCS range 13-15, no PTA, loss of consciousness $<20$ minutes) and matched controls were included in the study [24]. Patients were tested within a month of injury $(\mathrm{M}=26.6$ days) and 3 months post-injury. Mild TBI (mTBI) patients performed more poorly than controls on the MIST task within the first month following injury, which indicated that PM impairment is part of the acute cognitive dysfunction profile of mTBI. PM dysfunctions were also observed after 3 months post-injury, suggesting that PM may be a sensitive indicator of cerebral compromise in mTBI patients. Taken together, these studies conducted with mild and severe TBI patients [24, 45, 58, 69] showed a consistent deficit on the MIST summary score and total number of errors. Both TBI patients and controls demonstrated higher performance when they executed activities after a short time delay. Better performance was obtained with event-based than with time-based tasks in both TBI patients and controls. The controls demonstrated higher performance for action responses compared to verbal responses, though no effect of response type was observed in TBI patients. Overall, the MIST demonstrated good validity and test-retest reliability when performed across a two-week interval [70]. The split half reliability was .70 (Spearman-Brown coefficient), internal reliability (Cronbach's alpha $=0.89$ ) of the six subscales was high, but the internal reliability (Cronbach's alpha $=.47$ ) for each trial was poor.

The Royal Prince Alfred Prospective Memory Test (RPA-ProMem) includes three alternative forms, each of which has two time-based (i.e., "in 15 minutes time I would like you to tell me it's time for a coffee break") and two event-based tasks (i.e., "At the end of our session today, I would like you to ask me for an information sheet on note-taking strategies") that have to be performed within the session (short-term: "In 15 minute interval I would like you to remind me to move my cat so I don't get the ticket") or at a later moment (long-term: "When you arrive home today, I want you to phone and leave a message on my voice mail, telling me your mother's name") [69]. External aids are permitted during the testing session. The RPA-ProMem was used with 20 patients with brain lesions (stroke $n=7$, epilepsy $n=5$, tumour/cyst $n=2$, TBI $n=2$, arteriovenus malformation removal $n=2$, encephalitis $n=1$ and systemic lupus erythematosus $n=1$ ) and 20 controls [69]. Participants also performed the MIST, CAMP section A, and EMQ. Patients with brain lesions showed lower performance on the RPA-ProMem compared to controls, even when they rated their own PM performance in daily life as normal. No differences were found between the scores of the three parallel form of RPA-ProMem, and they showed good alternate form reliability (Spearmen-Brown coefficient $=.71$ ). These finding 
are consistent with those obtained from studies with self-report questionnaires [3, 61] and support the use of RPA-ProMem as an objective clinical measure of PM performance.

Finally, Virtual Week was developed as a laboratory PM task that would more closely represent PM activities in everyday life [43]. Two clocks are placed above and below the dice. The clock above the dice is a chronometer that starts at the beginning of each virtual day and the clock below is a virtual clock that moves when participants roll the dice and indicates the virtual time of the day (the clock moves 15 minute every two squares). Participants are required to perform 10 activities every virtual day. The original version [43] included 7 virtual days, but the later versions include 3 or 5 days and maintained task validity [71]. A training day is included at the beginning of the task to familiarize patients with task procedures. Interestingly, Virtual Week also includes regular and irregular tasks. Every virtual day, participants are required to perform 4 regular tasks that simulate regular activities that occur as one undertakes normal health care duties every day (i.e. "take medications every day at breakfast"), and 4 irregular tasks that simulate the kinds of occasional activities that are new (i.e., Monday: pick up the laundry when shopping). Within the regular and irregular tasks, two are time-based (i.e., "call the plumber at $3 \mathrm{pm}$ ") and two are event-based (i.e., "return the book to Philip when you see him").. We tested 18 TBI patients (age $\mathrm{M}=31.72$ years; GCS M $=4.54$, time since injury $\mathrm{M}=66.94$ months) and 18 controls with Virtual Week and other neuropsychological tasks [44]. Results showed a generalized PM impairment in TBI patients, and significant correlations were found between PM performance, indices of cognitive recovery (Level of Cognitive Functioning and Functional Independence Measure/Functional Assessment Measure), and semantic fluency. These results indicated that participants with better cognitive recovery obtained better PM performance. Since the first publication [43], Virtual Week has been widely used with healthy and clinical populations [71], with corresponding evidence indicated good psychometric properties [71, 72]. The reliability of Virtual Week was investigated in a study that involved younger and older adults [72]. Across the entire sample, reliability estimates ranged from .84 to .94 for the regular, irregular, and time-check tasks. In another study, the split-half reliability for the overall Virtual Week measure was estimated to be: 74 in a clinical group with schizophrenia [73]. In a recent study, test-retest reliability was investigated in older adults by use of the same (Study 1) or parallel (Study 2) versions across two testing time points separate by 1 month [74]. Preliminary results in Study 1 showed good internal consistency (Cronbach's alpha) of .64 at the initial and .83 at the retest session. In Study 2, for version A, internal consistency was .70 at the initial test and .89 at the retest session, and for Version B was .82 at the initial test and .65 at the retest session.

\section{Prospective memory trainings}

Traditionally, the rehabilitation of memory impairment in TBI patients has focused on retrospective memory. Only recently has the importance of PM impairments following TBI been recognized and resulted in the development of specific training programs [17, 18]. Considering that PM is not a unitary process, it is difficult to address the optimal rehabilitation paradigm that can be solely focused on treating PM as a unitary system, or can focus on treating 
specific PM components. In this section, we review the main rehabilitation approaches (Remedial vs. Compensatory) used in the treatment of PM impairment.

\subsection{Remedial/Restorative approaches}

Cognitive interventions have been developed to restore "the underlying defective cognitive functions usually via repetitive drills or training activities designed to stimulate damaged neural networks or establish new networks" [61, pp 9]. The first studies investigated the effect of repeating PM tasks after different retention intervals on PM performance. The Spaced Retrieval Technique (SRT) required participants to remember a task over an interval of time. If the task was recalled correctly, the retention interval was an increase. The SRT was tested with two TBI patients over 4.5 and 3.5 months of training. Results showed positive effects on PM performance, in fact, TBI patients increased their performance from being unable to complete a PM task following a 60 seconds delay to being able to complete a PM task following 8 minute delay, for patients 1; and an increment from 4 to 8 minutes delay was observed in patients 2 [75]. Based on these encouraging results, the authors further investigated the generalization effects of SRT with one TBI patient [76]. The training paradigm consisted of repetitive administration of PM tasks, with systematic lengthening of the delay period between task administration and task execution. Probes were taken that evaluated generalization to performance on naturalistic PM and retrospective memory tasks. Results confirmed previous findings and showed that patients were able to increment of temporal interval between task administration and task execution an maintain good PM performance. However, the results were less encouraging as tasks showed poor ecological validity [76]. Moreover, two TBI patients were tested with SRT training and retrospective memory drills [77]. The first patient increased the delay interval from 1 to 5 minutes, while the second patient increased the delay interval from 2 to 10 minutes. Results were consistent across the two TBI patients who showed improvement on PM task performance at the delayed target time in both experimental and real-life settings. A more ecologically valid training program called the Prospective Memory Re-training Package (PMRP) was developed [78]. Six TBI patients were first tested with the Prospective Memory Screening test (PROMS) [75] and then were trained on the PMRP. The training required the patients to perform real-life activities (i.e., putting a stamp on an envelope) at specified target times, with a maximum delay of 6 minutes. The delay between task administration and task execution increased depending on correct or incorrect responses. Results showed better PM performance after 2 months of training [78]. In addition, positive effects were found when space retrieval was combined with Error Learning (EL) technique, which was achieved by the discouragement of participants from guessing if they were uncertain of a response [79].

The effects of cognitive strategies on PM performance were also investigated [80]. Some authors showed that participants had better performance on PM tasks when they had previously made a strong and explicit association between PM cue and intended action through imagining themselves performing that PM action. By reinforcing the cue-action association during the encoding phase, future intentions are more likely to be supported by automatic cognitive processes according to the McDaniel \& Einstein's Multiprocess Model [4]. The 
authors [4] showed that less attentional resources and executive processes are required to perform the PM action because the intended action is spontaneously retrieved when the prospective cued is encountered. Following this finding, a training program was developed with visual imagery technique [81]. The training included three successive phases. The first phase evaluated the individual visual imagery capacity, the second focused on acquisition of visual imagery skills using spaced retrieval techniques, and the third focused on visual imagery techniques that are progressively applied to real-life situations in order to promote learning transfer. During the third phase, participants are encouraged to identify challenging daily-life situations and to develop more appropriate visual imagery strategies to successfully complete the real-life activities. Twenty-one patients with various brain injuries were included in the study: 12 participants were included in the control group (age $M=36.6$ years; time since injury $=60$ months) and 9 were included in the experimental group using visual imaginary technique (age $M=41.9$ years; time since injury $=65$ months). Participant included in the control group performed different memory trainings respective with the training used in their centre. The trainings were different for each patient, but intensity and frequency of training were the same in both groups. Results showed that visual imagery training significantly improved delayed recall of everyday verbal information (i.e., stories, appointments). Relatives also reported a reduction in PM problems and the effects were stable after a 3-month follow-up. Successive, visual imagery technique was used with 30 severe TBI patients [82]; 10 of who were assigned to the experimental condition using visual imaginary technique (age $\mathrm{M}=35.00$ years; PTA $=30.60$ days; time since injury $=43.40$ months) and 20 to the control condition (age $\mathrm{M}=$ 30.90 years; PTA $=29.20$ days; time since injury $=34.00$ months). The program required the patients to learn flexible cognitive strategies by creating gradually more complex and ecological associations between cue and intended action that could be used in real life situations. Participants who took part in the rehabilitation program improved their PM performance (measured by Test écologique de mémoire prospective; TEMP [83]), and also reported the use of imagery techniques in everyday life situations with corresponding improvement in PM function. Relatives also confirmed this improved performance [82].

The positive results obtained with visual imagery techniques seem to rely on the strong cueaction association and engagement required by the training. Repeated imagination of the retrieval situation and increased cue-action association might increase the detection of retrieval cues with the occurrence of the situation. This technique seems to be particularly effective for event-based PM tasks in which the PM cue is available. For time-based actions, maybe additional effort is needed and patients should try to associate a visual cue even if the action is time-based. For example, if the action is to make a call at $3 \mathrm{pm}$, participants should look at the phone and remember to make the phone call. Thus, imagination may help to translate a time-based into an event-based task. However, such a transference of time to an event based task presumably will only be possible in patients with mild impairment.

Some studies have attempted to resolve PM dysfunction with a different approach. Considering that PM is not a unitary system [4], one line of rehabilitation might be to restore the components of PM. These approaches followed the idea that retrospective memory and/or executive dysfunction may underlie PM impairment [16, 25, 27], and that improvement of 
these cognitive components should result in better PM performance [84]. Hypothetically, training programs devoted to improve attention, working memory, and executive functions could have positive effects on PM performance [3, 61, 84]. In general, approaches to the rehabilitation of executive deficits have focused on training patients to follow step-by-step problem solving strategies (i.e., define the problem and generate potential solutions) [85]. Positive effects were found when retrospective memory dysfunctions were rehabilitated [86, 87]; however, the value of such an approach for PM improvement remains to be investigated. Other studies have found that structured group experience facilitate the PM rehabilitation. Participants who enrolled in Goal Management Training (GMT) were encouraged to highlight common executive difficulties and discover which were the best strategies (i.e., breaking down goals into sub-goals, using mental imagery) [88]. Attempts to promote generalization included homework exercises and recording of everyday errors [85, 89]. Despite efforts to foster generalization and maintenance, the everyday benefits of such training still largely depend on strategies that spontaneously "come to mind" in everyday life [90]. Remedial strategies seem to work on the mental organization and encoding of prospective actions that should help recall. However, PM not only involves encoding and storing the content of PM action, but also recalling the intended action at the appropriate moment in the future. The remedial strategies previously presented may have more application to the rehabilitation of PM by enhancing recall of the content (the retrospective component) than enhancement of the intention. These techniques have demonstrated good effects on PM performance but need to be further developed in line with PM models and real life situations [1, 4, 5, 91]. For example, training paradigms need to include both event- and time-based tasks, with the knowledge that routine tasks (i.e., daily regular tasks [43]) can be better encoded, remembered, and performed. Novel activities can be difficult to remember, but in such cases researchers and clinicians can manipulate the salience of the PM cue [4, 72]. Preliminary data suggested that PM training based on remedial strategies can improve individual's PM performance, but further research is needed to investigate the generalizability to real-life situations.

\subsection{Adaptive/Compensatory approaches}

In contrast to the remedial approaches that are aimed to restore the impaired PM function, adaptive/compensatory strategies are aimed to compensate the PM dysfunction. These techniques are widely used in clinical practices and patients often spontaneously report the use of compensatory strategies such as a timer or diary. Memory aids are widely available, can be inexpensive, and have the potential to be highly effective in compensating for PM problems in mild to moderately impaired patients. Although patients can find it difficult to learn and remember to use such aids, it is possible to implement an effective system, even in patients with profound amnesia [61].

There is a substantial body of evidence supporting the use of external memory devices [90, 92], which can be categorized into non-electronic and electronic external memory devices. Nonelectronic memory devices include a diary, calendar, and to-do lists. These are easily available, but are only beneficial if patients make the effort to use them at the appropriate time [92]. Despite the fact that patients often spontaneously report to take notes on calendar and use a 
pin-board, very few studies have investigated the effectiveness of non-electronic memory devices on PM rehabilitation. Of the few conducted. one study used a memory book in training with TBI patients with amnesic disorders [93]. Patients were first introduced to the different functions and learned how to use the memory book. Then, patients used the memory book in a controlled laboratory environment followed by use in everyday life. Patients had to demonstrate mastery of criteria before they moved to the next step (use the memory book in reallife condition). For severe patients, the training lasted 6 months. Memory improvement was observed and effects were stable over a long time period. Previous results were extended to evaluate the effectiveness of the memory book in comparison to a more social therapy in which patients were trained with problem-solving strategies [94]. Eight TBI patients were randomly assigned to one of the two experimental conditions: memory book (mean age $=29.9$ years; days of coma $=39.7$; time since injury $=77.7$ months) and supportive therapy (mean age $=26.8$ years; days of coma $=37.5$; time since injury $=86.8$ months). After the training, the authors reported reductions in the number of errors in everyday life in patients who used the memory book. However, 6-months later, there were no longer differences between the two groups. This may raise the problem of generalization and long-term use of learned memory strategies. Some authors have noted that many patients quickly abandon diary use once they are discharged [95]. To overcome such problems, several formal training approaches worked also on selfawareness of PM deficits in order to minimize patients' resistance to use memory aids when back in their home environment. In fact, some studies showed the importance of involving family and friends in the training and the need to have practice sessions in community-based settings [96]. Taken together, these results are encouraging regarding the utility of nonelectronic memory aids; also, a later study showed that participants who spontaneously took notes (13 out of 36 people with brain injury and 14 out of 28 controls) performed significantly better on a PM test than those who did not take notes [63]. Results lead to the conclusion that note-taking significantly benefits PM performance. The suggestion is therefore to integrate non-electronic memory aids in other memory training programs such as group or remedial therapies $[3,92,97]$.

Considering the increasing use of electronic devices in everyday life, it has been observed a consequent increase of electronic memory devices in clinical training and PM rehabilitation. Electronic memory devices have the clear benefit of not merely telling the patients what he/she is intended to do, but also drawing the patient's attention to this information at the appropriate time. A brief summary of electronic memory aids in PM training for TBI patients is provided in Table 3.

Probably the most used and commercialized electronic memory device used to compensate for PM deficits is the NeuroPage system [98, 99, 100], which enables an individual to receive timed reminders or cues that appear on a portable pager carried by the person. The aim is to help individuals maintain independence by reminding them to carry out everyday tasks. Messages appear on a big screen and the user can control the system with a single large button, which makes the NeuroPage suitable for patients with motor difficulties. Messages have to be confirmed by the patients by calling the central system, in the case of no answer, the message is displayed again. All messages are also stored in the central system. The authors also 


\begin{tabular}{|c|c|c|c|}
\hline Memory Aids & References & Advantages & Disadvantages \\
\hline NeuroPage & {$[98,99,100]$} & $\begin{array}{l}\text { Very small and little learning is } \\
\text { required. The system can ring or } \\
\text { vibrate and a text message appeared } \\
\text { on the screen. }\end{array}$ & $\begin{array}{c}\text { The appointments are changed } \\
\text { through a paging company and } \\
\text { user cannot change them. }\end{array}$ \\
\hline $\begin{array}{l}\text { Mobile Extensible } \\
\text { Memory and } \\
\text { Orientation Sustem } \\
\text { (MEMOS) }\end{array}$ & {$[102,103,104]$} & $\begin{array}{l}\text { Therapists and caregivers can access } \\
\text { to the system from any computer with } \\
\text { internet and modify to encode data. }\end{array}$ & $\begin{array}{l}\text { Problem with connection } \\
\text { between server and devices. }\end{array}$ \\
\hline Memojog & {$[105,106]$} & $\begin{array}{l}\text { Users, therapists and caregivers can } \\
\text { access to the system. Possibility to add } \\
\text { others information beside PM tasks } \\
\text { (i.e. birthdays, addresses). }\end{array}$ & $\begin{array}{l}\text { Problem with connection } \\
\text { between server and devices. } \\
\text { Difficulties with touch screen } \\
\text { system. }\end{array}$ \\
\hline Voice Organizer & {$[107,108]$} & $\begin{array}{c}\text { User can autonomously record new } \\
\text { messages. }\end{array}$ & $\begin{array}{l}\text { Patients with speech and motor } \\
\text { impairments might have } \\
\text { difficulties in using the system. }\end{array}$ \\
\hline Palmtop & [109] & $\begin{array}{c}\text { User can autonomously add new } \\
\text { messages. }\end{array}$ & $\begin{array}{l}\text { Too difficult to use for patients } \\
\text { with severe impairments }\end{array}$ \\
\hline
\end{tabular}

Table 3. Overview of electronic memory devices.

presented the results of a large study conducted with 143 patients aged between 8 and 83 years [98]. All patients had brain damage (mainly TBI or stroke) and memory, attentional, and planning deficits. Results showed that patients generally benefitted from the use of NeuroPage with improvement in everyday goals by an average of $30 \%$ when the pager was used relative to baseline performance. Importantly, in the same patients, there was evidence that the benefits persisted when the system was no longer used, except in those with more pronounced executive impairment $[84 ; 98,99,101]$. Many patients suggested the pager served as a training function (i.e., consolidating intentions into a everyday life).

The Mobile Extensible Memory and Orientation System (MEMOS) [102, 103, 104] is a system specially designed for patients with brain injuries. The system includes a central server to communicate with a personal memory assistant over a wireless cellular phone. Similar to the NeuroPage, MEMOS includes a large screen with few buttons to accommodate patients with cognitive and motor impairments. Of interest, the device allows patients to leave messages for future appointments that are transferred to the central system where the caregiver can input them. The system sends reminders for PM tasks with feedback and step-by-step guidance. Important tasks, as taking medication, can be set as "critical tasks" for which the caregivers can be advised if the patient executed them.. The effectiveness of MEMOS was compared with a Palm organiser in 13 patients with brain injury [104]. Patients reported positive effects from both devices, but during the interview after the training, patients reported that the MEMOS was more helpful in the execution of PM tasks and desired to continue using it. The long-term 
use of MEMOS was evaluated with 3 TBI patients [103]. The authors reported that the MEMOS alone was unable to compensate for memory deficits in patients with severe TBI. For those patients, additional support for relatives is necessary [103].

Another interesting memory aid is Memojog $[105,106]$, which is similar to the MEMOS device [102]. Memojog is a remote and interactive communication system that provides prompting for people with memory impairments. A central system is used to deliver text prompts to a mobile device that are announced by an alarm. Interestingly, both the user and the caregivers can add new information into the devices from any internet station. Also, new tasks can be phoned in by others to add them into the system. The reminders are then wirelessly transmitted at the appropriate times and users have to respond to them. As for MEMOS, "crucial tasks" can be monitored with particular attention. Moreover, the system can record other information such as birthdays, addresses, contact information, pictures, and details of any appointments. Limitations of the system are the connectivity problems, thus authors and caregivers are unsure if the patients are doing something wrong or if the system is malfunctioning. Besides that, users (both older adults and patients with brain injury) are motivated by the system and haven shown improvement in memory performance with Memojog [106].

Also commercialised are systems in which it is possible to record messages that are played back at the appropriate time. One of them, Voice Organiser is a phone-type device that requires no input messages trough the central system, but the user can autonomously add new task and reminders [107]. Five TBI patients (mean age $=42.6$ years; time since injury $=38.6$ months) were trained in an A-B-A experimental design and performance was monitored for 9 weeks. Results showed that all but one patient improved in PM performance. The improvement was evident immediately at the beginning of the training. A limitation of the Voice Organiser device is that patients with significant speech disorders or poor motor ability might have difficulties in using it. In such conditions, relatives can program the system [107]. More recently, 8 patients with brain damage (mean age 46.25 years) and PM impairments were trained with an IC Recorder for a maximum of 3 months [108]. The names of the experimenter and patients were said before the alarm to attract attention and motivate the user. Soon after, the recorded message was said, indicating the task to be performed. Results showed that tasks prompted by the IC Recorder were better remembered and executed for five of the eight patients. The study added further support to thehigh quality of memory aids and suggested that the IC Recorder has great potential as a voice memory aid to assist patients with PM impairments [108].

Finally, microcomputers can be used to facilitate everyday PM performance. They have the advantage to be hand-held computers that can be easily carried around. Moreover, they provide visual as well as auditory messages to prompt the PM actions. Twelve patients (11 TBI patients and 1 with cerebrovascular accident; mean age $=49.6$ years) were trained with a palmtop organiser and evaluated at follow-up between 2 months and 4 years after initial training [109]. Participants were asked about prior experiences with computer devices, then whether the device was useful, and if and how often they still used it. Nine out of 12 patients reported that the palmtop computer was very useful during the training, and they were still using it. Of the remaining three patients, 1 never learned how to use it and 2 found no appropriate situation in their daily life where use it. Later PM performance was investigated 
in 12 patients (mean age $=4$ years; time since injury $=49.5$ months) using Palm organiser or mobile phone. The authors were not only interested in training PM performance, but also in training patients to enter appointments into the devices. The study showed that only patients with mild impairment were able to correctly enter the appointments [110].

The electronic market moves very quickly and memory devices need to be updated accordingly. We would like to report two interesting devices tested with older adults, but that can be extremely promising with patients with brain injuries: Autominder [111] and Coach [112]. Autominder is a mobile robot platform with an integrated screen display and portable mobile device designed to assist older adults in their home. As with the other memory systems, Autominder transmits reminders for PM activities, but interestingly has the ability to adapt to the user's schedule depending on the behaviour detected by sensors installed throughout the home. Coach consists of a video camera installed in the home and provides support for both prospective and retrospective memory deficits. In fact, Coach provides cues to initiate future actions and helps users to execute the action by suggesting the procedure step-by step. Interestingly, Coach is requires no learning on its use and thus has limited demands of the patient in terms interfacing with the device. The system verbally communicates the reminders so no reading is required. The advantages from using these systems are clear and users showed improvement in their PM performance. However, for some older adults, technology is still intimidating and work with it may generate apprehension. Future generations would benefit more from high quality technology $[3,84,92,113]$.

\section{General conclusion and future directions}

This chapter reviewed the literature regarding assessment and treatment of PM impairment in TBI patients. Dysfunctions in PM are often observed in TBI patients, they can be very frustrating and limit the independence of TBI patients, causing them to rely on caregivers for prompting. Moreover, these failures may affect their chance to return to work or start new activities after injury $[2,17,18]$. The PM impairment in TBI patients may be due to underling dysfunctions in working memory, inhibition, and executive functions [16, 22, 25, 28, 29].

Evaluation of PM performance in clinical setting was initially assessed with questionnaires, the most known are the PMQ [20], CAPM [54] and PRMQ [59]. Questionnaires have the advantage to be easly administrated, but they are unreliable and non-objective measures of PM dysfunction [47]. Despite some previous studies that have provided good reliability and validity of questionnaires $[3,56,60,61]$, the results are mixed when self-rated scores are compared with laboratory-based measures on PM performance. The main issue concerning the employment of questionnaires to evaluate PM performance is the impairment in selfawareness that is often observed in TBI patients $[22,47]$ that might compromise the validity their responses to the questions.

Laboratory based tests to investigate PM performance have also been developed. The most popular are the RBMT [62], CAMPROMPT [45], and MIST [58]. More recently, to overcome the limitation of a few numbers of trials observed in the previous tests, two new testes have 
been developed: Virtual Week [71] and RPA-ProMem [69]. These tasks have the advantage of assessing PM performance under more controlled conditions. Nevertheless, they often lack ecological validity. More studies should be dedicated to develop reliable and ecologically valid measures to assess PM performance in clinical settings. The evolution of new technologies might help in this direction (i.e., virtual reality) to bridge the gap between performance in experimental controlled settings and real life situations. Researchers also need to develop PM test according to PM models $[4,32,91]$ and ensure measurement of both event-based and timebased activities.

In terms of PM rehabilitation, two main approaches can be followed: remedial and compensatory. Remedial strategies are dedicated to restore the underlying cognitive functions with the intent to restore the damage neural networks or to create new networks. Compensatory strategies are implemented to modify the environment to overcome patients' limitations [3, 84, 92]. Most patients report the use of calendars and diaries to keep track of their duties, but these tools are limited as they require the patient to initiate using them. Electronic memory devices have the advantage to attract attention and display messages that indicate the action that has to be conducted. The most popular and commercialized electronic memory devices are the NeuroPage [98] and MEMOS [102], but many more devices are available, and some have the option to record messages as Voice organizer, [108] and add birthdays, addresses, or photos $[105,106,109]$. However, the problem with electronic devices may be that most patients are unable to learn how to properly operate them. This may be of less relevance in upcoming years when there are more individuals who are familiar with the use of such technological devices.

Aside from technology, however, the most relevant aspect seems to be whether or not patients are aware of their deficits, and therefore willing to use any kind of compensatory strategy. In any case, training with memory aid needs to be integrated into a more general neuropsychological treatment. Before administering any kind of treatment, the therapist needs to analyze what the patient is capable of accomplishing in everyday life. Therapy has to reflect the fact that acceptance of any device is highly related to awareness and acceptance of impairment.. In addition, external memory aids may be combined with other compensatory strategies such as changes in work behaviors and management of work breaks. Finally, caregivers need to work together with patients and and the treatment team to identify the more suitable memory aids and training.

\section{Appendix A}

Description of neuropsychological tests and questionnaires included in the studies.

\section{Full name}

Characteristics

\section{NEUROPSYCHOLOGICAL TESTS}




\begin{tabular}{|c|c|c|}
\hline WCST & $\begin{array}{l}\text { Wisconsin Card Sorting } \\
\text { Test }\end{array}$ & $\begin{array}{l}\text { The materials included four stimulus cards and two identical } \\
\text { decks of } 64 \text { fixed sequence response cards. Participants were } \\
\text { required to place the card according to a criterion and they were } \\
\text { notified only whether the responses were right or wrong. Once } \\
10 \text { consecutive correct matches are made, the sorting criterion is } \\
\text { changed, without warning. }\end{array}$ \\
\hline COWAT & $\begin{array}{l}\text { The Controlled Oral Word } \\
\text { Association Test }\end{array}$ & $\begin{array}{l}\text { It is measures rapid strategy formation, organization, cognitive } \\
\text { flexibility and generation of words given a phonetic (letter) cue } \\
\qquad(C, F, L \text { or F, A, S, depending on the study). }\end{array}$ \\
\hline VERBAL FLUENCY & & $\begin{array}{l}\text { The test includes phonemic and semantic sub-tests. In the } \\
\text { phonemic sub-test participants are required to produce word } \\
\text { starting with a certain letter (as in the COWAT). In the semantic } \\
\text { sub-test participants are required to produce word part of a } \\
\text { category (animal, cities and color). }\end{array}$ \\
\hline TOL & Tower of London & $\begin{array}{l}\text { Participants are presented with a standard array of four colored } \\
\text { disks (white, yellow, blue and black) on three pegs of varying } \\
\text { lengths and asked to achieve a given arrangement in a stated } \\
\text { number of moves by shifting the disks one at a time from one peg } \\
\text { to another. }\end{array}$ \\
\hline \multicolumn{3}{|c|}{ Attention } \\
\hline TMT (Part A and B) & Trail Making Test & $\begin{array}{c}\text { Required participants to rapidly draw lines between } 25 \\
\text { consecutively numbered circles or between alternating numbers } \\
\text { and letters. }\end{array}$ \\
\hline Stroop & & $\begin{array}{l}\text { Participants were instructed to identify the color of the central } \\
\text { word. Two possible conditions (congruent and incongruent) are } \\
\text { included. In the congruent condition, the color of the central } \\
\text { word corresponded with the written word; whereas, in the } \\
\text { incongruent condition, the written word appeared in a different } \\
\text { font color. }\end{array}$ \\
\hline RUFF $2 \& 7$ & & $\begin{array}{l}\text { Participants are asked to cross out the digits } 2 \text { and } 7 \text { in two } \\
\text { conditions. In one condition, the } 2 \text { s and } 7 \mathrm{~s} \text { are randomly } \\
\text { interspersed among other digits, and in the second condition the } \\
\text { distractors are made up of alphabetical letters. }\end{array}$ \\
\hline \multicolumn{3}{|c|}{ Memory } \\
\hline LNST & $\begin{array}{l}\text { Letter-Number Sequencing } \\
\text { Test }\end{array}$ & $\begin{array}{l}\text { It involves the auditory presentation of lists of letters and } \\
\text { numbers. Participants are then required to repeat the numbers } \\
\text { first in ascending order, and then the letters in alphabetical order. }\end{array}$ \\
\hline Digit Span & $\begin{array}{l}\text { Digit Span (Backward and } \\
\text { forward from Wechsler } \\
\text { Memory Scale) }\end{array}$ & $\begin{array}{l}\text { Participants were required to immediately recall strings of } \\
\text { numbers that increased in length (maximum score 16). }\end{array}$ \\
\hline
\end{tabular}




\begin{tabular}{|c|c|c|}
\hline Word List & $\begin{array}{l}\text { Word Lists sub-tests from } \\
\text { the Wechsler Memory } \\
\text { Scale }\end{array}$ & \\
\hline LM & $\begin{array}{l}\text { Logical Memory sub-test } \\
\text { from Wechsler Memory } \\
\text { Scale }\end{array}$ & $\begin{array}{l}\text { The task includes immediate (LM-I) and 30-min delayed (LM-II) } \\
\text { prose recall. }\end{array}$ \\
\hline N-Back & & $\begin{array}{l}\text { Common bi-syllabic word stimuli are presented sequentially. } \\
\text { Participants were instructed to press a designed keys to indicate } \\
\text { when they recognized a word that was the same as one of the N } \\
\text { words back. }\end{array}$ \\
\hline HVLT & $\begin{array}{c}\text { The Hopkins Verbal } \\
\text { Learning Test }\end{array}$ & $\begin{array}{c}\text { The test includes three learning trials of } 12 \text { orally presented } \\
\text { words. A yes/no recognition task was administered immediately } \\
\text { following learning trial. }\end{array}$ \\
\hline
\end{tabular}

\begin{tabular}{|c|c|c|}
\hline $\begin{array}{l}\text { Verbal declarative } \\
\text { memory }\end{array}$ & & \\
\hline Story sub-test of RBMT & & $\begin{array}{l}\text { Recall a short passage, both immediately and after a delay of } \\
\text { approximately } 15 \text { minutes. }\end{array}$ \\
\hline$R A V L T$ & $\begin{array}{l}\text { Rey Auditory Verbal } \\
\text { Learning Test }\end{array}$ & $\begin{array}{l}\text { Learning and recalling lists of words both immediately and after a } \\
\text { delay. }\end{array}$ \\
\hline \multicolumn{3}{|l|}{$\begin{array}{l}\text { Visual declarative } \\
\text { memory }\end{array}$} \\
\hline $\begin{array}{l}\text { Pictures, faces and routes } \\
\text { sub-tests of RBMT }\end{array}$ & & $\begin{array}{c}\text { Participants have to remember a series of } 10 \text { line drawings of } \\
\text { common objects and to identify them from a larger group of } 20 \\
\text { drawings; remember five photographs, which they had to identify } \\
\text { from a set of } 10 \text { photographs, finally, retracing a five-part } \\
\text { pathway around the room. }\end{array}$ \\
\hline \multicolumn{3}{|l|}{ QUESTIONNAIRES } \\
\hline DASS & $\begin{array}{l}\text { The Depression, Anxiety, } \\
\text { Stress Scales }\end{array}$ & $\begin{array}{l}\text { Three self-report scales designed to measure the } \\
\text { negative emotional states of depression, anxiety and stress. }\end{array}$ \\
\hline DEX & $\begin{array}{l}\text { The Dysexecutive } \\
\text { Questionnaire from } \\
\text { Behavioral assessment of } \\
\text { the dysexecutive syndrome } \\
\text { (BADS) }\end{array}$ & $\begin{array}{l}\text { 20-item questionnaire focusing on the symptoms of dysexecutive } \\
\text { syndrome. }\end{array}$ \\
\hline $\mathrm{BDI}$ & Beck Depression Inventory & $\begin{array}{l}\text { Self-report questionnaire in which each item consists of four } \\
\text { statements indicating different levels of severity of a particular } \\
\text { symptom experienced over the past week. Scores for all items are } \\
\text { summed to yield a single depression score. }\end{array}$ \\
\hline
\end{tabular}




\section{Author details}

Giovanna Mioni ${ }^{1,2^{*}}$, Shawn M. McClintock ${ }^{3}$ and Franca Stablum ${ }^{2}$

*Address all correspondence to: mioni.giovanna@gmail.com

1 École de Psychologie, Université Laval, QC, Canada

2 Department of General Psychology, Padova, Italy

3 Neurocognitive Research Laboratory, Division of Brain Stimulation and Neurophysiology, Department of Psychiatry and Behavioral Sciences, Duke University School of Medicine, Department of Psychiatry, UT Southwestern Medical Center, USA

\section{References}

[1] Ellis JA. Prospective Memory or the Realization of Delayed Intentions: A Conceptual Framework for Research. In: Brandimonte M, Einstein GO, McDaniel MA (eds.) Prospective memory: Theory and Applications. Mahwah, NJ: Lawrence Erlbaum; 1996. p1-22.

[2] Kliegel M, McDaniel MA, Einstein GO. (eds). Prospective Memory: Cognitive, Neuroscience, Developmental, and Applied Perspective. Mahwah, NJ: Lawrence Erlbaum; 2008.

[3] Shum D, Levin H, Chan RCK. Prospective Memory in Patients with Closed Head Injury: A Review. Neuropsychologia 2011; 49 2156-2165.

[4] McDaniel MA, Einstein GO. Strategic and Automatic Processes in Prospective Memory Retrieval: A Multiprocess Framework. Applied Cognitive Psychology 2000; 14 127-144.

[5] Kliegel M, Martin M, McDaniel MA, Einstein GO. Complex Prospective Memory and Executive Control of Working Memory: A Process Model. Psychologische Beiträge 2002; 44 303-318. 
[6] Ellis JA, Freeman JE. Ten Years of Realizing Delayed Intentions. In: Kliegel M, McDaniel MA, Einstein GO. (eds.) Prospective Memory: Cognitive, Neuroscience, Developmental, and Applied Perspective. Mahwah, NJ: Lawrence Erlbaum; 2008. p1-22.

[7] Henry JD, Phillips LH, Crawford JR, Kliegel M, Theodorou G, Summers, F. Traumatic Brain Injury and Prospective Memory: Influence of Task Complexity. Journal of Clinical and Experimental Neuropsychology 2007; 1 1-10.

[8] Meacham JA, Leiman B. Remembering to Perform Future Actions. In Neisser U. (ed.) Memory Observed: Remembering in Natural Contexts. San Francisco: W. H. Freeman; 1982. p327-336.

[9] Einstein GO, Holland LJ, McDaniel MA, Guynn MJ. Age-Related Deficits in Prospective Memory: The Influence of Task Complexity. Psychology and Aging 1992; 7 471-478.

[10] Guynn MJ, McDaniel MA, Einstein GO. Prospective Memory: When Memories Fail. Memory and Cognition 1998; 26 287-298.

[11] Carlesimo GA, Formisano R, Bivona U, Barba L, Caltagirone C. Prospective Memory in Patients with Severe Closed-Head Injury: Role of Concurrent Activity and Encoding Instructions. Behavioural Neurology 2004; 22 101-110.

[12] Einstein GO, McDaniel MA. Normal Aging and Prospective Memory. Journal of Experimental Psychology: Learning, Memory and Cognition 1990; 16 717-726.

[13] McDaniel MA, Guynn MJ, Glisky EL, Rubin SR, Routhieaux BC. Prospective Memory: A Neuropsychological Study. Neuropsychology 1999; 13 103-110.

[14] McFarland CP, Glisky EI. Frontal Lobe Involvement in a Task of Time-based Prospective Memory. Neuropsychologia 2009; 47 1660-1669.

[15] Stuss DT. Traumatic Brain Injury: Relation to Executive Dysfunction and the Frontal Lobes. Current Opinion in Neurology 2011; 24, 584-589.

[16] Mioni G, Stablum F, McClintock SM, Cantagallo A. Time-based Prospective Memory in Severe Traumatic Brain Injury Patients: The Involvement of Executive Functions and Time Perception. Journal of the International Neuropsychological Society 2012; 18, 697-705.

[17] Fleming JM, Shum D, Strong J, Lighthouse S. Prospective Memory Rehabilitation for Adults with Traumatic Brain Injury: A Compensatory Training Program. Brain Injury 2005; 19 1-13.

[18] Fleming JM, Riley L, Gill H, Gullo MJ, Strong J, Shum D. Predictors of Prospective Memory in Adults with Traumatic Brain Injury. Journal of the International Neuropsychological Society 2008; 14 823-831. 
[19] Kliegel M, Eschen A, Thöne-Otto AIT. Planning and Realization of Complex Intentions in Traumatic Brain Injury and Normal Aging. Brain and Cognition 2004; 5643 54 .

[20] Hannon R, Adams P, Harrington S, Fries-Dias C, Gibson MT. Effects of Brain Injury and Age on Prospective Memory Self-rating and Performance. Rehabilitation Psychology 1995; 40 289-297.

[21] Bisiacchi PS. The Neuropsychological Approach in the Study of Prospective Memory. In: Brandimonte M, Einstein GO, McDaniel MA. (eds.) Prospective Memory: Theory and Applications. Mahwah, NJ: Lawrence Erlbaum; 1996. p297-317.

[22] Kinsella GJ, Murtagh D, Landry A, Homfray K, Hammond M, O’Beirne L, Dwyer L, Lamont M, Ponsford, J. Everyday Memory Following Traumatic Brain Injury. Brain Injury 1996; 10 499-507.

[23] McDaniel MA, Einstein GO. Prospective Memory: An Overview and Synthesis of an Emerging Field. Thousand Oaks, CA: Sage; 2007.

[24] Tay SY, Ang BT, Lau XY, Meyyappan A, Collinson SL. Chronic Impairment of Prospective Memory After Mild Traumatic Brain Injury. Journal of Head Trauma 2010; 27 77-83.

[25] Shum D, Valentine M, Cutmore T. Performance of Individuals with Severe Longterm Traumatic Brain Injury on Time-, Event-, and Activity-based Prospective Memory Tasks. Journal of Clinical and Experimental Neuropsychology 1999; 21 49-58.

[26] Kinch J, McDonald S. Traumatic Brain Injury and Prospective Memory: An Examination of the Influence of Executive Functioning and Retrospective Memory. Brain Impairment 2001; 2 119-130.

[27] Mathias JL, Mansfield KM. Prospective and Declarative Memory Problems Following Moderate and Severe Traumatic Brain Injury. Brain Injury 2005; 4, 271-282.

[28] Maujean A, Shum D, McQueen R. Effect of Cognitive Demand on Prospective Memory in Individuals with Traumatic Brain Injury. Brain Impairment 2003; 4 135-145.

[29] Schmitter-Edgecombe M, Wright MJ. Event-based Prospective Memory Following Severe Closed-head Injury. Neuropsychology 2004; 18 353-361.

[30] Spreen O, Strauss E. A Compendium of Neuropsychological Tests (2nd ed.). New York: Oxford University Press; 1998.

[31] Maater CA, Sohlberg MM, Crinean J. Focus on Clinical Research: Perceptions of Memory Function in Individuals with Closed-head Injury. Journal of Head Trauma Rehabilitation 1987; 2 74-84.

[32] Kliegel M, McDaniel MA, Einstein GO. Plan Formation, Retention, and Execution in Prospective Memory: A New Approach and Age-related Effects. Memory and Cognition 2000; 28 1041-1049. 
[33] Knight RG, Titov N. Use of Virtual Reality Tasks to Assess Prospective Memory: Applicability and Evidence. Brain Impairment 2009; 10 3-13.

[34] Burgess PW, Alderman N, Forbes C, Costello A, Coates LM, Dawson DR, Anderson ND, Gilbert SJ, Dumotheil I, Channon, S. The Case for the Development and Use of 'Ecologically Valid' Measures of Executive Function in Experimental and Clinical Neuropsychology. Journal of the International Neuropsychological Society 2006; 12 194-209.

[35] Titov N, Knight RG. A Video-based Procedure for the Assessment of Prospective Memory. Applied Cognitive Psychology 2001; 15 61-83.

[36] Titov N, Knight RG. A Procedure for Testing Prospective Remembering in Persons with Neurological Impairment. Brain Injury 2000; 14 877-886.

[37] Titov N, Knight RG. A Computer-based Procedure for Assessing Functional Cognitive Skills in Patients with Neurological Injury: The Virtual Street. Brain Injury 2005; $19315-322$.

[38] Knight RG, Harnett M, Titov N. The Effects of Traumatic Brain Injury on the Predicted and Actual Performance of a Test of Prospective Remembering. Brain Injury 2005; 19 27-38.

[39] Knight RG, Titov N, Crawford M. The Effects of Distraction on Prospective Memory Remembering Following Traumatic Brain Injury Assessed in a Simulated Naturalistic Environment. Journal of the International Neuropsychology Society 2006; 12 8-16.

[40] Kinsella GJ, Ong B, Tucker J. Traumatic Brain Injury and Prospective Memory in a Virtual Shopping Trip Task: Does it Matter who Generates the Prospective Memory Target? Brain Impairment 2009; 10 45-51.

[41] Ellis JA, \& Kvavilashvili, L. Prospective memory in 2000: Past, Present and Future Directions. Applied Cognitive Psychology 2001; 14 1-9.

[42] Bertsch S, Pesta BJ, Wiscott R, McDaniel MA. The Generation Effect: A Meta-analytic Review. Memory \& Cognition 2007; 35 201-210.

[43] Rendell PG, Craik FIM. Virtual and Actual week: Age-related Differences in Prospective Memory. Applied Cognitive Psychology. Special Issue: New Perspective in Prospective Memory 2000; 14 S43-S62.

[44] Mioni G, Rendell PG, Henry JD, Cantagallo A, Stablum F. An Investigation of Prospective Memory Functions in People with Traumatic Brain Injury Using Virtual Week. Journal of Clinical and Experimental Neuropsychology (in press).

[45] Fleming JM, Kennedy S, Fisher R, Gill H, Gullo M, Shum D. Validity of the Comprehensive Assessment of Prospective Memory (CAPM) for Use with Adults with Traumatic Brain Injury. Brain Impairment 2009; 1, 34-44. 
[46] Fleming JM, Doig E, Katz N. Beyond Dressing and Driving: Using Occupation to Facilitate Community Integration in Neurorehabilitation. Brain Impairment 2000; 1 141-150.

[47] Fleming JM, Strong J, Ashton R. Self-awareness of Deficits in Adults with Traumatic Brain Injury: How to Best Measure? Brain Injury 1996; 10 1-15.

[48] Gilewski MJ, Zelinski EM. Memory Functioning Questionnaire. Psychopharmacology Bulletin 1988; 24 665-670.

[49] Hermann DJ, Neisser U. An Inventory of Everyday Memory Experience. In: Gruneberg MM, Morris PE, Sykes NR (eds.) Practical Aspects of Memory. New York: Academic Press; 1978.

[50] Broadbent DE, Cooper PF, FitzGerald P, Parkes KR. The Cognitive Failures Questionnaire and its Correlates. British Journal of Clinical Psychology 1982; 21 1-16.

[51] Sunderland A, Harris JE, Gleave J. Memory Failures in Everyday Life Following Severe Head Injury. Journal of Clinical Neuropsychology 1984; 6 127-142.

[52] Bennett-Levy J, Powell GE. The Subjective Memory Questionnaire: An Investigation into the Self-reporting of 'Real Life' Memory Skills. British Journal of Social and Clinical Psychology 1980; 19 177-188.

[53] Buchnan T, Ali T, Hefferman TM, Ling J, Parrott AC, Rodgers J, Scoley AB. Nonequivalence of On-line and Paper and-pencil Psychological Tests: The Case of the Prospective Memory Questionnaire. Behavior Research Methods 2005; 37 148-154.

[54] Roche NL, Fleming JM, Shum D. Self-awareness of Prospective Memory Failure in Adults with Traumatic Brain Injury. Brain Injury 2002; 16 931-945.

[55] Chau L, Lee J, Fleming J, Roche N, \& Shum D. Reliability and Normative Data for the Comprehensive Assessment of Prospective Memory (CAPM). Neuropsychological Rehabilitation 2007; 17 707-722.

[56] Roche NL, Moody A, Szabo K, Fleming JM, Shum D. Prospective Memory in Adults with Traumatic Brain Injury: An Analysis of Perceived Reasons for Remembering and Forgetting. Neuropsychological rehabilitation 2007; 17 314-334.

[57] Wilson BA, Emslie H, Foley J, Shiel A, Watson P, Hawkins K, Groot Y, Evans J. The Cambridge Prospective Memory Test, London: Harcourt; 2005.

[58] Raskin SA. Memory for Intentions Screening Test: Psychometric Properties and Clinical Evidence. Brain Impairment 2009; 1 23-33.

[59] Smith G, Della Sala S, Logie RH, Maylor EA. Prospective and Retrospective Memory in Normal Ageing and Dementia: A Questionnaire Study. Memory 2000; 8311-321. 
[60] Kliegel M, Jäger T. Can the Prospective and Retrospective Memory Questionnaire (PRMQ) Predict Actual Prospective Memory Performance? Current Psychology: Developmental, Learning, Personality and Social Fall 2006; 25 182-191.

[61] Shum D, Fleming J, Neulinger K. Prospective Memory and Traumatic Brain Injury: A Review. Brain Impairment 2002; 3 1-16.

[62] Wilson BA, Cockburn JM, Baddeley AD. The Rivermead Behavioural Memory Test. Bury St Edmunds: Thames Valley Test Co; 1985.

[63] Groot YCT, Wilson BA, Evans J, Watson P. Prospective Memory Functioning in People with and without Brain Injury. Journal of the International Neuropsychological Society 2002; 8 645-654.

[64] Mills V, Kixmiller JS, Gillespie A, Allard J, Flynn E, Bowman A, Brawn CM. The Correspondence between the Rivermead Behavioural Memory Test and Ecological Prospective Memory. Brain and Cognition 1997; 35 322-325.

[65] Makatura TJ, Lam C, Leahy BJ, Castillo M, Kalpakjian C. Standardized Memory Tests and the Appraisal of Everyday Memory. Brain Injury 1999; 13 355-367.

[66] Wilson BA, Clare L, Baddeley AD, Cockburn J, Watson P, Tate R. The Rivermead Behavioural Memory Test Extended Version (RBMT-E). Bury St Edmunds: Thames Valley Test Company; 1999.

[67] Wills P, Clare L, Shiel A, Wilson BA. Assessing Subtle Memory Impairments in the Everyday Memory Performance of Brain Injured People: Exploring the Potential of the Extended Rivermead Behavioural Memory Test. Brain Injury 2000; 14 693-704.

[68] Delprado J, Kinsella G, Ong B, Pike K, Ames D, Storey E, Saling M, Clare L, Mullaly E, Rand E. Clinical Measures of Prospective Memory in Amnesic Mild Cognitive Impairment. Journal of the International Neuropsychological Society; 2012; 18 295-304.

[69] Radford KA, Lah S, Say M, \& Miller LA. Validation of a New Measure of Prospective Memory: The Royal Prince Alfred Prospective Memory Test. The Clinical Neuropsychology 2011; 25 127-140.

[70] Woods SP, Moran LM, Dawson MS, Carey CL, Grant I, The HIV Neurobehavioral Research Center (HNRC) Group. Psychometric characteristics of The Memory for Intentions Screening Test. Clinical Neuropsychology 2008; 22 864-878.

[71] Rendell PG, Henry JD. A Review of Virtual Week for Prospective Memory Assessment: Clinical Implications. Brain Impairment 2009; 10 14-22.

[72] Rose NS, Rendell PG, McDaniel MA, Abele I, Kliegel M. Age and Individual Differences in Prospective Memory During a "Virtual Week": The Role of Working Memory, Task Regularity and Cue Focality. Psychology and Aging 2010; 25 595-605.

[73] Henry JD, Rendell PG, Kliegel M, Altgassen M. Prospective Memory in Schizophrenia: Primary or Secondary Impairment? Schizophrenia Research 2007; 95 179-185. 
[74] Mioni G, Stablum F, Rendell PG, Gamberini L, Bisiacchi PS. Test-retest Reliability of Virtual Week: A Task to Investigate Prospective Memory (in preparation).

[75] Sohlberg MM, White O, Evans E, Mateer C. Background and Initial Case Studies into the Effects of Prospective Memory Training. Brain Injury 1992a; 6 129-138.

[76] Sohlberg MM, White O, Evans E, Mateer C. An Investigation of the Effects of Prospective Memory Training. Brain Injury 1992; 6 139-154.

[77] Raskin SA, Sohlberg MM. The Efficacy of Prospective Memory Training in Two Adults with Brain Injury. Journal of Head Trauma Rehabilitation 1996; 11 32-51.

[78] Hannon R, Feliciano L, Messner A. Prospective Memory Retraining in Adults with Traumatic Brain Injury. Archives of Clinical Neuropsychology (abstract).

[79] Kixmiller JS. Evaluation of Prospective Memory Training for Individuals with Mild Alzheimer's Disease. Brain and Cognition 2002; 49 237-241.

[80] Chasteen AL, Park DC, Schwarz N. Implementation Intentions and Facilitation of Prospective Memory. Psychological Science 2001, 12, 457-461.

[81] Kaschel R, Della Salla S, Cantagallo A., Fahlböck A, Laaksonen R, Kazen M. Imagery Mnemonics for the Rehabilitation of Memory: A Randomised Group Controlled Trial. Neuropsychological Rehabilitation 2002; 12 127-153.

[82] Potvin MJ, Rouleau I, Sénéchal G, Giguère JF. Prospective Memory Rehabilitation Based on Visual Imagery Techniques. Neuropsychological Rehabilitation 2011; 21 899-924.

[83] Potvin MJ, Rouleau I, Audy J, Charbonneau S, Giguère, JF. Ecological Prospective Memory Assessment in Patients with Traumatic Brain Injury. Brain Injury 2011; 25 192-205.

[84] Fish J, Wilson BA, Manly T. The Assessment and Rehabilitation of Prospective Memory Problems in People with Neurological Disorders: A review. Neuropsychological rehabilitation 2010; 20 161-179.

[85] von Cramon, DY, Matthes-von Cramon GM, Mai N. Problem-solving Deficits in Brain Injured Patients: A Therapeutic Approach. Neuropsychological Rehabilitation 1991; 1 45-64.

[86] Hutchinson J, Marquardt TP. Functional Treatment Approaches to Memory Impairment Following Brain Injury. Topics in Language Disorders 1997; 18 45-57.

[87] Raymond MJ, Malia KB, Bewick KC, Bennett TL. A Comprehensive Approach to Memory Rehabilitation Following Brain Injury. The Journal of Cognitive Rehabilitation 1996; 14 18-23. 
[88] Levine B, Robertson IH, Clare L, Carter G, Hong J, Wilson BA, et al. Rehabilitation of Executive Functioning: An Experimental Clinical Validation of Goal Management Training. Journal of the International Neuropsychological Society 2000; 6 299-312.

[89] Levine B, Schweizer T, O'Connor C, Turner G, Gillingham S, Stuss DT, Manly T, Robertson IH. Rehabilitation of Executive Functioning in Patients with Frontal Lobe Damage with Goal Management Training. Frontiers in Human Neuroscience 2011; 5-9.

[90] Bellezza FS. Mnemonic Devices: Classification, Characteristics, and Criteria. Review of Educational Research Summer 1981; 51 247-275.

[91] Smith RE, Persyn D, Butler P. Prospective Memory, Personality, and Working Memory: A Formal Modeling Approach. Zeischrift fur Psychologie 2011; 219 108-116.

[92] Thöne-Otto AIT, Walther K. Assessment and Treatment of Prospective Memory Disorders in Clinical Practice. In: Kliegel M, McDaniel MA, Einstein GO. (eds.) Prospective Memory: Cognitive, Neuroscience, Developmental, and Applied Perspective. Mahwah, NJ: Lawrence Erlbaum; 2008. p321-345.

[93] Sohlberg MM, Mateer CA. Training Use of Compensatory Memory Books: A Three Stage Behavioural Approach. Journal of Clinical and Experimental Neuropsychology 1989; 11 871-91.

[94] Schmitter-Edgecombe M, Fahy JF, Whelan JP, Long CJ. Memory Remediation After Severe Closed Head Injury: Notebook Training Versus Supportive Therapy. Journal of Consulting Clinical Psychology 1995; 484-489.

[95] Lynch WJ. You must Remember this: Assistive Devices for Memory Impairment. Journal of Head Trauma Rehabilitation 1995; 10 94-97.

[96] Burke JM. Danick JA, Bemis B, Durgin CJ. A Process Approach to Memory Book Training for Neurological Patients. Brain Injury 1994; 8 71-81.

[97] Ownsworth TL. McFarland K. Memory Remediation in Long-term Acquired Brain Injury: Two Approaches in Diary Training. Brain Injury 1999; 13 605-626.

[98] Wilson BA, Evans JJ., Emslie $\mathrm{H}$ et al. Evaluation of NeuroPage: A New Memory Aid. Journal of Neurology, Neurosurgery and Psychiatry 1997; 113-115.

[99] Wilson BA, Emslie HC, Quirk K, Evans JJ. Reducing Everyday Memory and Planning Problems by Means of a Paging System: A Randomised Control Crossover Study. Journal of Neurology, Neurosurgery, and Psychiatry 2001; 70 477-482.

[100] Evans JJ, Emslie H, Wilson BA. External Cueing System in the Rehabilitation of Executive Impairments of Action. Journal of the International Neuropsychology Society 1998; 4 399-408.

[101] Fish J, Manly T, Emslie H, Evans JJ, Wilson BA. Compensatory Strategies for Acquired Disorders of Memory and Planning: Differential Effects of a Paging System 
for Patients with Brain Injury of Traumatic versus Cerebrovascular Aetiology. Journal of Neurology, Neurosurgery, and Psychiatry 2008; 79 930-935.

[102] Walther K, Schulze H, Thöne-Otto A. An Interactive Memory Aid Designed for Patients with Head Injury: Comparing MEMOS with Two Commercially Available Electronic Memory Aids. Poster at First Congress of the European Neuropsychological Societies in Modena, Italy, April 2004.

[103] Walther K, Thöne-Otto AIT. Long-term Usage of the Interactive Memory Aid System MEMOS. Poster presented at the Second International Conference on Prospective Memory, Zurich, Switzerland. Retrieved August 23, 2005.

[104] Thöne-Otto AIT, Walther K. Evaluation of MEMOS, an Interactive Memory Aid System for Brain Injured Patients: Personal Memory Assistant vs. Palm Organizer. Poster presented at the Second International Conference on Prospective Memory, Zurich, Switzerland. Retrieved August 23, 2005.

[105] Morrison K, Szymkowiak A, Gregor P. "Memojog-An Interactive Memory Aid Incorporating Mobile Based Technologies." Mobile Human-Computer Interaction-MobileHCI 2004. Springer Berlin Heidelberg, 2004. 481-485.

[106] Szymkowiak A, Morrison K, Gregor P, Shah P, Evans JJ, Wilson BA. A Memory Aid with Remote Communication Using Distributed Technology. Personal and Ubiquitous Computing 2005; $91-5$.

[107] van den Broek MD, Downes J, Jhonson Z, Dayus B, Hilton N. Evaluation of an Electronic Memory Aid in the Neuropsychological Rehabilitation of Prospective Memory Deficits. Brain Injury 2000; 14 455-462.

[108] Yasuda K, Misu T, Beckman B, Watanabe O, Ozawa Y, Nakamura T. Use of an IC Recorder as a Voice Output Memory Aid for Patients with Prospective Memory Impairment. Neuropsychological Rehabilitation 2002; 12 155-166.

[109] Kim HJ, Burke DT, Dowds MM, Boone KA, Park GJ. Electronic Memory Aids for Outpatient Brain Injury. Brain Injury 2000; 14 187-196.

[110] Thöne-Otto AIT, Walther K. How to Design an Electronic Memory Aid for Brain Injured Patients: Considerations on the Basis of a Model of Prospective Memory. International Journal of Psychology 2003; 38 236-244.

[111] Pollack ME, Brown L, Colbry D, McCarthy CE, Orosz C, Peintner B, Ramakrishnan S, Tsamardinos I. Autominder: An Intelligent Cognitive Orthotic System for People with Memory Impairment. Robotics and Autonomous Systems 2003; 44 273-282.

[112] Mihailidis A, Fernie GR, Claghorn WL. The Development of a Computerized Cueing Device to Help People with Dementia to be More Independent. Technology and Disability 2000; 13 23-40. 
[113] Caprani N, Greaney J, Porter N. A Review of Memory Aid Devices for an Ageing Population. PsychNology Journal 2006; 4 205-243.

[114] Shum D, Sweeper S, Murray R. Performance on Verbal Implicit and Explicit Memory Tasks Following Traumatic Brain Injury. The Journal of Head Trauma Rehabilitation 1996; 11 43-53. 